\title{
Andreas Arvidi disputatsioon De natura et constitutione medicinae arstiteadusliku mõtte arengu peegeldajana 17. sajandi Tartu ülikoolis $^{1}$
}

Kaarina Rein

\begin{abstract}
Teesid: Antud artikkel käsitleb rootsi luuleteoreetiku Andreas Arvidi (u 16201673) meditsiinialast disputatsiooni De natura et constitutione medicinae, mis kaitsti Tartu ülikoolis 1648. aastal, seega Academia Gustaviana ajajärgul.

Andreas Arvidi õppis Tartu ülikoolis loodusteadusi ning andeka tudengina disputeeris ta väga erinevatel teemadel. Tema arstiteaduslik töö selgitab sõna "meditsiin" tähendust ja defineerib meditsiini kui nähtust. Andreas Arvidi arutleb meditsiini leiutamise põhjuste ja eesmärkide üle ning esitab meditsiini jaotused. Kogu töös ilmutab autor suurepäraseid teadmisi kreeka ja rooma autorite tundmisel ning ka uuema meditsiinikirjanduse vallas.
\end{abstract}

Märksõnad: Andreas Arvidi Stregnensis, disputatsioonid 17. sajandil, meditsiiniajalugu, meditsiiniharidus rootsiaegses Tartu ülikoolis, óppetöö Academia Gustaviana Dorpatensises.

Enamikus 17. sajandi kõrgkoolidest mängis meditsiiniharidus teoloogia ja õigusteadusega võrreldes üpris tagasihoidlikku rolli. Võrdlemisi vähesed tudengid valisid arsti elukutse, sest haavaarste-kirurge oli igas väiksemaski linnas ning arstina oli raske töökohta leida (Tering 1984: 113). Ka Tartu Academia Gustavianas ja hilisemas Academia Gustavo-Carolinas oli arstiteaduskonnas tudengeid teiste teaduskondadega võrreldes väga vähe ning meditsiinialaste väitekirjade hulk on Tartu ülikoolis 17. sajandil olnud tühine. Need, kes lootsid arstina leiba teenida, pidid õppima tollastes kuulsaimates ülikoolides - Leidenis, Utrechtis, Paduas, Helmstedtis, Erfurdis või Jenas, kus oli olemas Theatrum anatomicum või mõni kliinik. Ka Liivimaale saabunud meedikud olid sageli õppinud just nendes kõrgkoolides. Rootsiaegse Tartu ülikooli kasvandikest on meditsiini alal olnud tegevad vaid 11 isikut: nendest kaheksa oli õppinud Academia Gustavianas ja kolm Academia Gustavo-Carolinas. Academia Gustavianas meditsiini õppinutest ja hiljem selles vallas tegutsenutest on kindlaks tehtud kaks juhtu - David Cunitius ja Olaus Oestenius (Tering 1984: 114). 
Mis puudutab väitekirju, siis kokku kaitsti rootsiaegses Tartu ülikoolis disputatsioone ja dissertatsioone 595. ${ }^{2}$ Peamine osa neist - 498 nimetust - langes Academia Gustaviana ajajärgule (Jaanson 2000: 42). Kõige rohkem kaitsti rootsiaegses ülikoolis väitekirju ootuspäraselt teoloogia alal (201), järgnesid filosoofia (194), loodusteadused (131), õigusteadus (33), filoloogia, poeetika, retoorika (21), ajalugu (10) ja lõpuks arstiteadus (5) (Jaanson 2000: 44). Nendest viiest meditsiinialasest tööst kaks kaitsti Academia Gustaviana päevil, kolm aga Academia Gustavo-Carolina ajal.

Otsus, milliseid tollastest töödest nimetada meditsiinialasteks, on kaheldav. Tartu ülikooli ajalugu puudutavates kirjutistes räägitakse tavaliselt viiest meditsiinialasest väitekirjast sellepärast, et mainitud tööde juhendajad olid meditsiiniprofessorid ning ka tööde pealkirjas kajastub asjaolu, et tegemist on meditsiinialase disputatsiooni või dissertatsiooniga. Kui arvestada, et üks meditsiinidisputatsioon kaitsti Tartus veel enne ülikooli avamist (aastal 1631) Tartu gümnaasiumi päevil ning arstiteaduslikke teemasid leidus ka loodusteaduslikes väitekirjades, mida kaitsti filosoofiateaduskonnas, võib meditsiini käsitlevate väitekirjade hulka Tartus 17. sajandil pidada siiski mõnevõrra suuremaks kui viis nimetust. ${ }^{3}$ Samas ei pruukinud meditsiinialaste tööde autoriks olla alati arstiteaduskonna üliõpilased ja see kehtib ka Andreas Arvidi disputatsiooni De natura et constitutione medicinae puhul. Et nimetatud disputatsioon on kaitstud Academia Gustaviana perioodil, keskendutaksegi artiklis edaspidi peamiselt rootsiaegse Tartu ülikooli esimese tegevusperioodiga seonduvale.

\section{Meditsiiniprofessorid Academia Gustavianas}

Uppsala ülikool tollase Rootsi ainsa teadusliku ülikoolina sai 17. sajandil Tartu ülikoolile eeskujuks (Käbin 1986: 21, Lill 1994: 97), kuid paraku oli sel ajal meditsiiniharidus sealgi puudulik (Johannisson 1989: 34). Esimesed meditsiiniprofessorid Tartus olid pärit saksa kultuuriruumist. Aastatel 1630-1656 jõudis Tartus töötada kolm meditsiiniprofessorit - Johannes Raicus, Johann Below ja Sebastian Wirdig, neist esimene oli promoveerunud meditsiinilitsentsiaadiks Wittenbergi ülikoolis, teistest olid saanud meditsiinidoktorid vastavalt Rostocki ja Königsbergi ülikoolis.

Esimene meditsiiniprofessor, kes Tartu ülikoolis tööle pidi asuma, oli endine Uppsala ülikooli professor, Böömimaalt pärit Johannes Raicus (?-1631), kes oli oma aja tuntud arstiteadlane ning Paracelsuse ${ }^{4}$ opetuse pooldaja (TÜA I 1982: 230). J. Raicus oli juba 1630. aastal määratud Tartu gümnaasiumi meditsiiniprofessoriks ning 1631. aaastal nimetati ta ka selle õppeasutuse Rector Magnificuseks, kuid paraku suri ta sama aasta detsembrikuus, seega enne 
ülikooli avamist (Brennsohn 1905: 324-325). Oma Tartu perioodil on J. Raicus koostanud Gustav II Adolphile pühendatud väitekirja Disputatio physico-medica

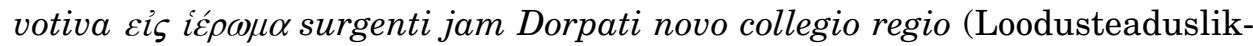
meditsiiniline pühendusdisputatsioon juba kerkivale Tartu uuele kuninglikule kolleegiumile), mille üle väitles Tartu gümnaasiumis 26. märtsil aastal 1631 Petrus Turdinus. ${ }^{5}$ J. Raicuse disputatsioon on jaotatud kaheks teemaks. Esimeseks teemaks on ülevaade Tartu ümbruse pinnase ja vee keemilisest koostisest, paikkonna endeemilistest haigustest ja nende ravist. Siinkohal lähtub J. Raicus Hippokratese ${ }^{6}$ teosest Õhust, veest ja elupaikadest, mis seab arstile tingimuseks, et kui too suundub võõrasse paika, peab ta uurima paikkonna pinnase, vee ja õhu loomust, et teha kindlaks, millest tulenevad vastava kandi endeemilised haigused (Hippokrates 1984: 70/71). Disputatsiooni teise teema all leiab käsitlemist mineraalvete kasutamine ravis (Raicus \& Turdinus 1631). J. Raicuse muude tähtsamate meditsiinialaste teoste loetelu on ära toodud näiteks J. F. v. Recke ja K. E. Napiersky koostatud biograafilises leksikonis (vt Recke \& Napiersky 1831).

Pärast J. Raicuse surma oli aastail $1632^{7}-1642$ Tartus meditsiiniprofessoriks Johann Below (1601-1668). Tema ajal Tartus meditsiiniüliõpilasi peaaegu polnudki, ühes 1638. aastal kirjutatud kirjas väidab J. Below ise, et on Tartus näinud vaid ühte meditsiinitudengit, kelleks oli David Cunitius (Tering 1984: 114). D. Cunitiusest sai hiljem Tallinna arst ja sealse gümnaasiumi poeesiaõpetaja (Tering 1984: 175), oma Tartu perioodil paistis ta silma produktiivse kreeka ja ladina keeles luuletajana (Päll 2003: 32). Johann Belowi professuuri ajal ei kaitstud Tartus ühtegi meditsiinidisputatsiooni, ${ }^{8} \mathrm{küll}$ aga peeti sel ajal kaks meditsiinilist oratsiooni - Fridericus Heiniuse "De medicina" (Meditsiinist) 1637. aastal ja Sigvardius Olai Wallanderi "De homine" (Inimesest) 1640. aastal. Pärast oma Tartu perioodi suundus J. Below kõigepealt Riiga, sealt aga Moskvasse, kus ta töötas 1651. aastani, olles Vene tsaaride Mihhail I Romanovi ja Aleksei I ihuarst. J. Belowi viimaseks elupaigaks sai tema õpingute linn Rostock (Magilnitski 1967: 183).

Aastail $1646^{9}-1654$ oli Tartu ülikooli meditsiiniprofessori ametis Sebastian Wirdig (1613-1687), kes oli õppinud Wittenbergi, Rostocki ja Königsbergi ülikoolis. Tema loengute erijooneks Tartus oli olnud psühhiaatria käsitlemine (TÜA I 1982: 231). S. Wirdig rõhutas psüühika tähtsust inimese tervisele ja haigusele ka oma hilisemas 1673. aastal Hamburgis välja antud raamatus Nova medicina spirituum (Uus spirituaalmeditsiin) ja teda võib pidada tänapäeva psühhosomaatilise meditsiini üheks varaseks eelkäijaks (TÜA I 1982: 232). Hiljem naasis S. Wirdig Rostocki ning oli 1655. aastast alates seal meditsiiniprofessor (Šaurums 1932: 20). 1671. aastast oli S. Wirdig hertsog Gustav Adolf von Mecklenburg-Güstrowi ihuarst (Brennsohn 1905: 433). 
S. Wirdigi juhendamisel valmiski Tartus kaks arstiteaduslikku disputatsiooni, mida peetakse ainsateks Tartus Academia Gustaviana perioodil kaitstud meditsiiniväitekirjadeks. Need kaks tööd olid Andreas Arvidi (u 1620-1673) disputatsioon De natura et constitutione medicinae (Meditsiini olemusest ja ülesehitusest) 1648. aastal ja Olaus N. Oesteniuse (1625-1682) väitekiri De dysenteria (Düsenteeriast) 1651. aastal. Oesteniuse disputatsiooni on V. Kalnin pikemalt käsitlenud Tartu Ülikooli ajaloo I osa IX peatükis "Arstiteadus ja loodusteadused" (TÜA I 1982: 231-232), kus sellele disputatsioonile on antud kõrge hinnang. Hiljem, 1657. aastal promoveerus Olaus Oestenius Helmstedti ülikoolis meditsiinilitsentsiaadiks dissertatsiooniga Disputatio medica de arthritide (Meditsiinialane disputatsioon artriidist, Triebs 1995: 147) ja töötas linnaarstina Göteborgis (Tering 1984: 254).

\section{Õppetöö ja disputatsioonid Academia Gustavianas}

Tudengite ülikooli vastuvõtmisega tegeles Academia Gustaviana põhikirja järgi filosoofiateaduskonna dekaan, kelle ülesandeks oli hoolsalt eksamineerides uurida ülikooli astuda sooviva tudengi kombeid, võimeid, edasijõudmist õpingutes, et otsustada, millisesse loenguteklassi tuleks too paigutada (Constitutiones 1997: 40/41). Tartu ülikooli suureks külgetõmbejõuks oli asjaolu, et siin ei nõutud õppemaksu, enamik üliõpilasi oli ühistoidul või sai stipendiumi (TÜA I 1982: 67).

17. sajandi Euroopa ülikool oli pigem õpetamise kui teadustöö tegemise koht (Jaanson 2000: 42). Põhiliseks õppetöö vormiks olid ladinakeelsed loengud, mis olid üliõpilastele kohustuslikud (TÜA I 1982: 62). Lisaks loengutele kujutas endast olulist õpetamise meetodit disputeerimis- ehk vaidlusoskuse arendamine, avalike kõnede koostamine ja esinemise harjutamine. Mõtete originaalsust väitekirjades otseselt ei nõutud. Eesmärgi püstitamise poolest jagunesid disputatsioonid kahte rühma: harjutusdisputatsioonid ja disputatsioonid akadeemilise kraadi taotlemiseks ehk disputationes pro gradu (Jaanson 2000: 42).

Ka Tartus oli dispuutide pidamine tehtud kohustuslikuks õppevormiks. Disputatsiooni teema ja idee andis juhendaja-professor, sageli ka oma uurimisteemast lähtuvalt ja disputeerimine toimus tema eesistumisel. Väitleja võis olla ka autor ise, sel juhul oli see märgitud tiitellehel või pöördel sõnadega auctor et respondens või muul viisil (Jaanson 2000: 43). Väitlemisel tutvustas eesistuja mõne sõnaga disputatsiooni ja kutsus oponendid, kellest igaühele lubati disputeerimiseks tund aega. Seejärel pidi respondent näitama vastuargumentide nõrkusi (Constitutiones 1997: 52/53). 
Lubatud ei olnud disputatsioonid, mis käsitlesid mõttetut ja jumalavallatut teemat või põhjustasid rahutusi. Väitlemisele eelneval päeval tuli disputatsioonid avalikult välja kuulutada ja professoritele eksemplarid välja jagada (Constitutiones 1997: 50/51). Tiitellehel oli kirjas disputatsiooni teema, eesistuja, väitleja, ülikooli nimi, kaitsmise koht, kuupäev ja sageli ka kellaaeg (Jaanson 2000: 44). Levinud oli komme avaldada trükitud väitekirjades kolleegide, kaasüliõpilaste, sõprade ja sugulaste õnnitlusi ehk gratulatsioone.

Akadeemilise hariduse eesmärk 17. sajandil ei olnud ettevalmistus mõne konkreetse ametiga tegelemiseks, vaid teadmiste omandamine magistrikraadi saamiseks (Tering 1984: 82). Neil, kes filosoofiateaduskonnast magistrikraadi tahtsid saada, kestis ametlik stuudium kuus aastat, kõrgemates fakulteetides tuli õppida veel kolm aastat (Tering 1984: 74). Enamasti polnud tudengitel võimalik nii kauaks ülikooli jääda ja ametlikult koha taotlemisel magistrikraadi ka ei nõutud, kuid sellegipoolest olid kraadiomanikud eelistatud (Tering 1984: 82-83). Academia Gustavianas kaitsti magistrikraad vähemalt 60 korral ning Academia Gustavo-Carolinas 29 korral. 17. sajandil leidis Tartu ülikoolis aset kaks teoloogialitsentsiaadi promotsiooni ja üks teoloogiadoktori promotsioon (Tering 1984: 84). Muudel aladel Tartus aastatel 1632-1710 litsentsiaadiega doktorikraade ei kaitstud, meditsiinis pole sellest ajast ka magistrikraade. Uppsala ülikoolis leidis esimene dokumenteeritud meditsiinidoktori promotsioon aset aastal 1738 (Käbin 1986: 22), Tartu ülikooli esimene meditsiinidoktori promotsioon toimus alles ülikooli taasavamisel 1802. aastal. ${ }^{10}$

Ladina keel oli 17. sajandil kõigi ülikoolidistsipliinide aluseks (Lill 1994: 102) ning ka väitekirjade keeleks oli ladina keel. Rootsiaegse Tartu ülikooli publikatsioonidest olid ladinakeelsed 82\% (Jaanson 2000: 53) ning nimetatud trükiste asukohaks on peamiselt Rootsi raamatukogud. Neist rikkalikemad on selles osas Stockholmi Kuninglik Raamatukogu ja Uppsala Ülikooli raamatukogu. Eesti sattumisel 1710. aastal Venemaa võimu alla viidi rootsiaegse Tartu ülikooli raamatukogu Stockholmi, kus see põhiosas liideti 1717. aastal Kuningliku Raamatukogu koosseisu. Aastaid kestnud kogumis- ja uurimistöö tulemusena on Tartu Ülikooli raamatukokku kogutud ülikooli varatrükiste koopiate kollektsioon, mis korvab originaalide puudumist (Jaanson 2000: 165). Nii eksisteerib ka Andreas Arvidi disputatsioon De natura et constitutione medicinae Tartus vaid koopiana, originaal paikneb aga Helsingi Ülikooli raamatukogus (Jaanson 2000: 294). Andreas Arvidi teistest Tartus peetud disputatsioonidest on enamasti säilinud mitu eksemplari ja need asuvad Rootsi raamatukogudes, mõni neist on esindatud ka Helsingi Ülikooli raamatukogus. See, et tema meditsiinialane töö on esindatud vaid Helsingis, on mõnevõrra üllatav, sest Andreas Arvidi isik pole kuidagi seotud Soomega. Oletada võib, et disputatsiooni sattumine Helsingisse on seotud töö lõpus oleva professor Johannes Gezeliuse $^{11}$ kirjutatud õnnitlusluuletusega. 


$$
\begin{aligned}
& \text { DISPUTATIO MEDICA } 29 \\
& \text { De } \\
& \text { NATURA ET } \\
& \text { CONSTITUTIONE } \\
& M E D I \cdot C I N A \text {; } \\
& \text { Quamin, } \\
& \text { DEO Duce \& Âficer, } \\
& \text { In almá Academia GUST A Vlaná eADOL. } \\
& \text { PHIna , qua Dorpati Livonorum efe ad Embecceas, in Aydicorio } \\
& \text { Majori, al dieñ 2. Septembrus Anno i } 6 \text { 4 B. boris } \\
& \text { aे } 7 . \text { matitutinis, } \\
& \text { Confensiente Amplijsimâ Facultate Medica, } \\
& \text { SUB PR ESIDIO } \\
& \text { Experientißimi Es Excellentißsimi Viri }
\end{aligned}
$$

Joonis 1. Disputatsiooni tiitelleht:

$$
\begin{gathered}
\text { DISPUTATIO MEDICA } \\
\text { De } \\
\text { NATURA ET } \\
\text { CONSTITUTIONE } \\
\text { MEDICINAE; } \\
\text { Quam }
\end{gathered}
$$

DEO Duce \& Auspice,

In alma Academia GUSTAVIana ADOL-

PHIna, quae Dorpati Livonorum est ad Embeccam, in Auditorio

Majori, ad diem 2. Septembris Anno 1648. horis

a 7. matitutinis,

Consentiente Amplissima Facultate Medica,

SUB PRAESIDIO

Experientissimi et Excellentissimi Viri

DN. SEBASTIANI Wirdig/ Medicinae

Doctoris, ejusdemque Professoris Publici nec non Faculta-

tis Medicae p. t. Decani, Praeceptoris et Fautoris sui

Reverenter colendi.

Publice ventilandam exhibet

Andreas Arvidi Stregnensis.

Dorpati Livonorum,

Imprimebat JOHANNES VOGELIUS, Acad. Typogr.

Anno M DC XLVIII 


\section{Andreas Arvidi}

Ehkki meditsiinialaseid väitekirju kaitsti rootsiaegses Tartu ülikoolis äärmiselt vähe, väärib märkimist asjaolu, et disputatsiooni De natura et constitutione medicinae autor Andreas Arvidi kuulub nende Tartu ülikooli kasvandikke hulka, kes on jäädvustunud kultuurilukku. Nimelt on Andreas Arvidi koostanud esimese rootsikeelse poeetikaõpiku Manuductio Ad Poesin Svecanam, mis on oluliselt mõjutanud Rootsi luulekunsti (Tering 1984: 123). Nimetatud teos avaldati Rootsis 1651. aastal, nii saksa kui ka taani poeetikast mõjutatuna toob see rootsi luulesse moodsad värsivormid nagu näiteks soneti. ${ }^{12}$ Seega on Andreas Arvidi Rootsi kirjanduse seisukohalt oluline isik.

Teadaolevad daatumid Andreas Arvidi õpingute ja hilisema karjääri kohta on ära toodud rootsiaegset Tartu ülikooli käsitlevas Album Academicumis (vt Tering 1984: 206). Tema üliõpilaspõlvest Tartus on eraldi artikkel (vt Sainio 1993: 277-284), mis on küll mõnevõrra ebaühtlane ja valikuline ega paku kaugeltki täielikku ülevaadet tema õpingutest. Andreas Arvidi Tartu perioodi kirjutiste bibliograafia võib leida M. A. Sainio ja E.-L. Jaansoni Tartu ülikooli 17. sajandi trükiseid käsitlevatest bibliograafiatest (vt Sainio 1978, Jaanson 2000). Märkimist on see väljapaistev rootslane leidnud ka Academia Gustaviana senati protokollides (vt Tering 1994: 278-281), paraku küll mitte positiivsest küljest, vaid oma aja probleemse ja konfliktse tudengina Tartus (vt Loit 2006: 139). Andreas Arvidi õpingutejärgsest elukäigust Rootsis ja tema teostest saab ülevaate Rootsi biograafilisest leksikonist (vt SBL 1918: 764-768).

Viimasel ajal on Andreas Arvidi Eesti teaduskirjanduses mainimist leidnud seoses talle Tartu ülikoolis pühendatud luuletustega (Viiding 2005: 455-461), ${ }^{13}$ muuhulgas ka nende gratulatsioonidega, mis said talle osaks disputatsiooni De natura et constitutione medicinae kaitsmisel.

Andreas Arvidi sündis umbes 1620. aastal Strängnäsi linna meeri Arvid Anderssoni pojana. Pärast kodulinna gümnaasiumi lõpetamist immatrikuleeriti ta 13. juunil 1642. aastal Tartu ülikooli (Sainio 1993: 277) pärast seda kui ta 10. juunil oli tasunud traditsioonilise sissemaksu (Tering 1984: 206). Võib mainida, et ajavahemikus 1632-1656 pärines peaaegu pool (468) Tartu ülikooli immatrikuleeritud tudengitest Rootsist, neist Andreas Arvidi kodukandist Södermanlandist 50, kõige rohkem oli üliõpilasi Smålandist. Kokku oli Academia Gustavianas tudengeid 1056 (Tering 1984: 24).

Suurel osal Tartu ülikooli astunutest puudus perekonnanimi ja noormehed kanti sisse isanime järgi ning nimed latiniseeriti. Päritolu koht märgiti kas linna või ajaloolise provintsi järgi, seega nimetati Strängnäsist pärinevat noormeest Stregnensiseks. Tartus õppis Andreas Arvidi Academia Gustaviana filo- 
soofiateaduskonnas loodusteadusi ning promoveerus 27. oktoobril 1648. aastal eetikaalase väitekirjaga filosoofiamagistriks. Vähem kui kaks kuud enne seda oli ta kaitsnud oma disputatsiooni De natura et constitutione medicinae.

Õpingutes oli Andreas Arvidi aktiivne ja edukas. Disputatsiooniga astus ta üles kuuel korral ning sellele lisaks pidas ta ülikoolis ka kaks oratsiooni ehk kõnet. ${ }^{14}$ Tartu ülikooli esimese tegevusperioodi jooksul aastail $1632-56$ astus vaid 320 tudengit üles kõnega või disputatsiooni respondendina, mis oli umbes $32 \%$ tudengite üldarvust. Andreas Arvidiga olid võrdsed või koguni ületasid teda vaid viis tudengit (Sainio 1993: 281). Disputatsioonide pidamine oli 17. sajandi ülikoolis tudengitele küll kohustuslik, kuid üliõpilased olid üsna liikuvad ja õppisid sageli mitmes ülikoolis järjest. Seega ei pruukinud nad oma kohustuslikke etteasteid sooritada just Tartus.

Andreas Arvidi oli väga mitmekülgne ja andekas tudeng, kes võis esineda nähtavasti ükskõik mis teemal. Nii on tema erinevate disputatsioonide ja oratsioonide teemaks olnud füüsika, astronoomia, matemaatika, botaanika, meditsiin, teoloogia ja eetika. ${ }^{15}$ Üsna paljud Academia Gustavianas kaitstud disputatsioonidest defineerivad mingi asja olemust ning on kirjutatud abstraktsetel teemadel (nt filosoofiast, füüsikast, elust ja surmast, suuremeelsusest, mõõdukusest, üllusest, kõneosavusest). Ka Andreas Arvidi tööd ei ole teemale lähenemise seisukohast erandid.

Andreas Arvidit on disputatsioonide puhul väitekirja autoriks nimetatud vaid tema meditsiinialase töö puhul, kuid mõningate disputatsioonide sarnane käekiri lubab oletada, et tegelikult on ta rohkemate tööde autor ning tema väitekirjade autorsuse väljaselgitamine nende keelt ja stiili analüüsides oleks omaette uurimisteema. Andreas Arvidi võimekuse osas on ka vastupidiseid arvamusi, nii leiab M. Sainio oma Andreas Arvidi üliõpilaspõlve puudutavas artiklis, et ükski Andreas Arvidi disputatsioonidest ega oratsioonidest pole tema enda koostatud ning tööde väga erinevaid teemasid arvestades ei saa midagi öelda Andreas Arvidi huvide kohta (Sainio 1993: 278).

Ent Andreas Arvidi pole Academia Gustaviana ajalukku jäädvustunud sugugi üksnes tubli ja aktiivse tudengina, mõningate allikate põhjal on pilt temast sootuks teistsugune. Nii on tema nimi äramärkimist leidnud Academia Gustaviana senati protokollides, kust selgub, et noormehele heideti 1644. aasta septembrikuus ette sagedast kõrtsides viibimist, prassimist ja joomapidudel osalemist. Vaatamata korduvatele lubadustele end parandada ei pidanud ta oma tõotust ega näidanud üles lugupidamist rektori vastu, kes oli teda korduvalt eraviisiliselt manitsenud. Peale selle ta müüs maha oma piibli ja prassis ka selle eest saadud raha läbi ning jättis kogu oma stipendiumi kõrtsidesse. Seetõttu otsustati arvata jumalakartuse hüljanud Andreas Arvidi maha Tema 
Kuningliku majesteedi stipendiumilt ning jätta linnamüüride piires aresti seniks, kuni ta on rahuldanud kõigi oma võlausaldajate nõudmised, vastasel korral ähvardas noormeest väljaheitmine (Tering 1994: 278/279, 280/281). 1645. aasta sügisel tuli Andreas Arvidil aga jälle ülikooli senati ees seista, seekord süüdistati teda kerglastes elukommetes ja õpingute unarussejätmises. Esimese süüdistuse põhjuseks oli Andreas Arvidi kooselu nn heast perekonnast tütarlapsega (Sainio 1993: 279). Viimase vanemate survel otsustati Andreas Arvidi 12. veebruaril 1647 viieks aastaks ülikoolist välja heita ning tema varandus konfiskeerida ja pitseerida (Sainio 1993: 280). Nähtavasti lühendati eemaloleku aega hiljem pooleteisele aastale, sest 1647. aastal astus Andreas Arvidi Tartus jällegi disputatsiooni respondendina üles. Neile pahandustele on ilmselt viidatud ka ühes Tartu ülikoolis Andreas Arvidile pühendatud luuletuses (Viiding 2005: 456-457).

Andreas Arvidi lahkus Tartust lõplikult 1649. aasta maikuus (Tering 1984: 206). Mõningatel andmetel alustas ta Tartus ka oma poeetikaõpikut (Sainio 1993: 283). Kodukanti tagasi pöördumisel sai Andreas Arvidist väärikas Rootsi kuningriigi kodanik. 1651. aastast oli ta Strängnäsi gümnaasiumis füüsika ja loogika lektor, 1653. aastal sai temast sama kooli rektor, sama aasta 11. detsembril ordineeriti ta vaimulikuks. 1658. aastast oli ta Österhaninge kirikuõpetaja ning 1668. aastast vaimulikuseisuse esindaja Rootsi riigipäevas (Tering 1984: 206). Peale nende ametite tegeles Andreas Arvidi ka Rootsi antikviteetide uurimise ja kogumisega (SBL 1918: 764).

Andreas Arvidi oli kaks korda abielus, esimesel korral Strängnäsi toompraosti Josef Fogdoniuse tütrega, tema teine abielu sõlmiti tema ja Södertälje praosti Johannes Johannis Wattrangiuse tütre vahel (SBL 1918: 764). Andreas Arvidi suri 1673. aastal.

\section{Disputatio medica de natura et constitutione medicinae}

Andreas Arvidi meditsiinialane disputatsioon on siiani uurijatele vähe huvi pakkunud, M. Sainio arvates ei ole see väitekiri meditsiinialane tavalises tähenduses (Sainio 1993: 277), V. Kalnin mainib selle Tartu Ülikooli ajaloo I osa IX peatükis "Arstiteadus ja loodusteadused" ainult ära ega lisa ühtegi kommentaari, vaid keskendub teisele S. Wirdigi juhendatud väitekirjale (TÜA I 1982: 231). Samas nimetab H. Trass Andreas Arvidi taimedealast disputatsiooni De Plantis kõige huvitavamaks botaanikaalaseks disputatsiooniks rootsiaegses Tartu ülikoolis (TÜA I 1982: 239). Selline vastandlik suhtumine tema 
kahte väitekirja äratab mõnevõrra imestust, sest tegelikult on Andreas Arvidi meditsiini- ja botaanikaalane töö ülesehituselt kaunis sarnased, üks püüab kindlaks määrata meditsiini, teine taimede olemust, kumbki ei tegele mingi konkreetse üksikküsimusega meditsiini või botaanika vallast.

Kui võrrelda Andreas Arvidi meditsiinialast disputatsiooni teiste Academia Gustavianas kirja pandud meditsiinialaste töödega, siis sarnaneb see sisu ja ülesehituse poolest ehk kõige rohkem Fridericus Heiniuse 30. oktoobril 1637 peetud oratsiooniga "De medicina" ("Meditsiinist"), mis samuti määratleb arstiteadust ning mille aines kattub osaliselt Andreas Arvidi disputatsioonis esitatuga. Samas tsiteerib F. Heinius oma kõnes peamiselt antiikautoreid ja piiblit, rõhutades Jeesus Kristuse osa ravimisel (Hein 1637). Andreas Arvidi töös on aga tähtsal kohal ka uuemad, s.o 16. ja 17. sajandi autorid.

Andreas Arvidi disputatsioon De natura et constitutione medicinae, (Meditsiini olemusest ja ülesehitusest) on peetud 1648. aasta 2. septembril kell 7 hommikul alma Academia Gustaviana Adolphina auditorium majuses meditsiinidoktor Sebastian Wirdigi eesistumisel. Väitekiri on pühendatud kuninganna Kristiinale ja trükitud Johann Vogeli (Johannes Vogeliuse) akadeemilises trükikojas. Teos kujutab endast harjutusdisputatsiooni ning Andreas Arvidi on selle töö auctor et respondens, so autor ja respondent ühes isikus. Väitekiri on jaotatud 38 peatükiks, lõpus lisandub kaheksa teesi, millele on antud kas jaatav või eitav vastus. Disputatsiooni kaitsmise puhul on Andreas Arvidit pühendusluuletustega õnnitlenud kolm inimest, kellest kaks olid Academia Gustaviana professorid Johannes Erici Stregnensis ja Johannes Gezelius, mis kahtlemata näitab tunnustust Andreas Arvidi isiku suhtes. J. Gezelius on kreeka keele professorina kirjutanud kreekakeelse gratulatsiooni, ülejäänud kaks luuletust on ladinakeelsed, gratulatsioonid on lisatud disputatsiooni tekstile.

Disputatsiooni sissejuhatuses (1.-3. ptk) ütleb Andreas Arvidi, et meditsiin pärineb jumaliku majesteedi aardekambrist, kuna selle abil võideldakse inimsoo kõige kurjemate vaenlaste, s.o haigustega ja säilitatakse elu võimalikult kaua kõigist haigustest ja vaevadest vabana.

Autor tsiteerib siinkohal Jean Ferneli (Joannes Ferneliust): ${ }^{16}$ Kui elu on kõigile surelikele kõige kallim, siis järelikult on väljapaistvaim see kunst, mis seda säilitab, hoiab ja kaitseb.

Mõiste "meditsiin” selgitamiseks jagab Andreas Arvidi disputatsiooni kolme ossa. Esimeses annab ta meditsiini definitsiooni, teises põhjused ning kolmandas selgitab meditsiini jaotusi. 


\section{Meditsiini defineerimine (ptk 4-17)}

Andreas Arvidi annab kaks meditsiini definitsiooni: nime ja nähtuse definitsioon. Sellega seoses tsiteerib ta 4 . sajandil $\mathrm{pKr}$ elanud kreeka kõnemeest ja filosoofi Themistiost, ${ }^{17}$ kelle väitel on nime tähendus kõikide uurimiste algus. Siinkohal lähtub Andreas Arvidi ka omaaegsest traditsioonilisest arusaamast, et asja või nähtuse tõelist või varjatumat olemust on võimalik mõista, kui tunda seda tähistava sõna päritolu ja tuletusalust.

Nime defineerimisel tuleb seega tähelepanu pöörata kolmele osale: etümoloogiale, homonüümiale ja sünonüümiale.

Mis puutub etümoloogiasse, siis tuleneb ladinakeelne sõna medicina verbist mederi, mis tähendab "haigetele appi tulema", see sõna aga ei sobituks täielikult, vaid väljendaks üksnes terapeutikat ehk ravimisõpetust, jättes välja selle osa meditsiinist, mis toetab olemasolevat tervist. Ent kuivõrd sünekdohhi teel (tähendusülekande teel osa ja terviku suhte alusel) saab selle sõna tähendust laiendada, peaks autori arvates üritama sobitada seda sõna kogu inimkeha tervise eest hoolitsemise kunstile.

Homonüümiat ehk sama kujuga sõnade eritähenduslikkust nimetavad filosoofid Andreas Arvidi sõnul segaduse loojaks. Laiemas tähenduses hõlmab meditsiin ka veterinaariat. Kitsamas tähenduses märgib ladinakeelne sõna medicina ravimit või ravivahendit, mida haige puhul kasutatakse.

Sünonüümiks antakse ladinakeelsele sõnale medicina väljend ars medendi

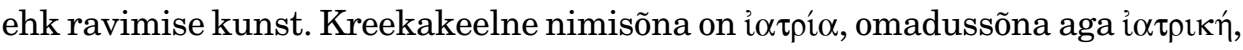

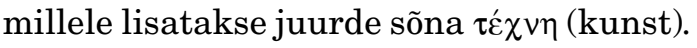

Erinevad autorid defineerivad meditsiini erinevalt. Wittenbergi ülikooli meditsiiniprofessorile, tuntud iatrokeemik Daniel Sennertile ${ }^{18}$ (Sennertusele) toetudes toob Andreas Arvidi ära järgmise definitsiooni: Meditsiin on kunst, mis niipalju kui võimalik, säilitab inimese olemasolevat tervist, ent kui see on kaotatud, taastab selle.

D. Sennerti tsiteerimine on oluline märk, sest ka teine S. Wirdigi eesistumisel disputeerinud üliõpilane Olaus Oestenius viitab oma väitekirjas $D e$ dysenteria paaril korral D. Sennertile. Selle põhjal võib järeldada, et D. Sennert oli Tartus autoriteet.

Andreas Arvidi märgib oma töös ära, et meditsiinil on oma eripära, ent tuleb siiski tähelepanu pöörata sellele, et meditsiin pole mitte kehaline kunst nagu maadlemine, tantsimine või odavise, vaid see eripära on vaimne, nagu on grammatikal, retoorikal ja loogikal. Aristoteles annab Nikomachose eetika 6. raamatu 4. peatükis kunstile järgneva definitsiooni: kunst on mõistuspärane loov seadumus (Aristoteles 1990: 334-335). Meditsiin vastab Andreas Arvidi arvates sellele Aristotelese kunstidefinitsioonile. 
Meditsiini objekt või subjekt on inimene, keda ravitakse. Meditsiini eesmärk on tervis.

\section{Põhjused meditsiini loomiseks (ptk 18-28)}

Teises jaotuses disputeerib Andreas Arvidi meditsiini (tekke)põhjuste ja eesmärkide üle.

Esimeseks toimivaks põhjuseks on Andreas Arvidi arvates jumal, kes on kõige hea autor, allikas ja algus. Teine toimiv põhjus, et rajada meditsiin, on leidlike inimeste - nagu Hippokrates, Galenos, ${ }^{19}$ Hermes Trismegistos $^{20}$ ja Paracelsus - olemasolu. Ent kes oli esimene arstiteaduse rajaja, pole kindel, sest selles asjas võib täheldada palju erimeelsusi. Ühtede antiikaja inimeste uskumuse kohaselt leiutas arstiteaduse Egiptusest pärinev kuningas Apis ${ }^{21}$, kreeka ajaloolane Diodoros ${ }^{22}$ aga omistab selle au egiptlaste jumalale Hermesele $^{23}$ (Thothile), Pliniuse ${ }^{24}$ järgi oli selleks Arabos, ${ }^{25}$ mõned aga arvavad, et Apollon ise oli meditsiini leiutaja, kuna ta väidab Ovidiuse ${ }^{26}$ teoses Metamorfoosid 1.521 enda kohta järgmist: Meditsiin on minu leiutatud, kogu maailmas kutsutakse mind abivalmiks.

Nende inimeste vaimuanded, kes meditsiini määratlemisega vaeva näevad, on erinevad, ja nad astuvad erinevaid teid pidi. Seetõttu on esile kerkinud erinevad arstide koolkonnad.

Autor nimetab siinkohal empiirilist, metoodilist, dogmaatilist ehk ratsionaalset ja spagiirikute koolkonda ning seletab lühidalt ka nende olemust ja erinevust üksteisest. Empiiriline koolkond peab vajalikuks haiguste ravimisel tähele panna vaid kogemust ja vaatlusi, selle koolkonna jagab Erasmus Bartholinu ${ }^{27}$ omakorda vanaks ja uueks. Vana koolkond otsustab ravivahendite üle kolme asja - isikliku vaatluse, ajaloolise kasutuse ja analoogia - põhjal. Uus koolkond määrab ravivahendeid ilma kogemuse ja analoogiata, ent selle koolkonna arstid väidavad siiski ülbelt, et nad tuginevad kogemusele. Teised aga leiavad, et nad peavad ravimisel piisavaks vaid hindamist seisundi põhjal ning on seetõttu aluse pannud metoodilisele koolkonnale. Veel on kuuldud arstidest, kes ühendavad ravimisel mõistuse kogemusega, nendest on tekkinud dogmaatiline ehk ratsionaalne koolkond, mida nende peamise patrooni Galenose järgi kutsutakse ka galeeniliseks. On veel neljandad, kes lähtuvad spagiirilistest tegevustest ja osade harmooniast, sarnasusest ning vaheldumisest mikro- ja makrokosmoses. Nendest on tekkinud spagiirikute koolkond, mida mõned nimetavad Hermes Trismegistose järgi ka hermetismiks, teised aga Paracelsuse koolkonnaks selle usina viljeleja Paracelsuse järgi. 
Meditsiini teise toimiva põhjuse juures tuleb autori arvates mainida veel looduslikku annet, siinkohal tsiteerib ta Hippokratese traktaati "Seadusest", kus on öeldud, et loodusele vastu seistes ei anna miski tulemusi (Hippokrates 1981: 262-263). Ning tõepoolest - ütleb disputatsiooni autor -, kellele pole looduse poolt antud annet meditsiiniga tegelemiseks, kuid kes üritab siiski seda kunsti õppida, see püüab sobitada hunte lambatalledega või madu ahviga. Ent seevastu inimene, kel on looduse poolt kalduvus meditsiiniga tegelemiseks, võib tunda rõõmu mõistmise õnne, otsuse õigsuse ja mälu usaldusväärsuse üle, tema võib selles ürituses suurepäraseid asju korda saata.

Õpetajad on meditsiini õppimisel äärmiselt vajalikud. Elavad on seejuures paremad kui tummad, s.o raamatute kaudu kättesaadavad korüfeed. Ent ka tummad on olulised, sest õppimise lähtepunkt ongi nende lugemine, kuid elavad peavad meid sel teel julgustama. Anatoomiat, diagnoosimist ning ravimite valmistamist tuleb autori arvates kindlasti õppida elava õpetaja juhendamisel.

Hoolsus ja harjutamine on meditsiini õppimisel väga kasulik. Sest ükskõik kui viljakas ka poleks põld, ei anna see saaki, kui seda ei harita. Väljapaistvaimadki vaimuanded ei või jõuda arstiteaduseni, kui neid ei kaunistata arstide kindlate ja täiuslike dogmadega.

Meditsiini esmane eesmärk on Andreas Arvidi arvates jumala nime ülistamine, teine on ravimine ja selle kaudu tervis. Viimast eesmärki arst alati ei saavuta, sest kõigi haigete tervist pole võimalik taastada. Selle väite illustreerimiseks tsiteerib autor jällegi rooma luuletajat Ovidiust, kes on väitnud sedasama. ${ }^{28}$ Sellele vaatamata täidab arst oma kohustust siiski rahuldavalt, kui ta midagi tegemata ei jäta nende ravimisel, kes on looduse ja kunsti võimuses, ütleb Andreas Arvidi, tsiteerides D. Sennertit.

\section{Meditsiini jaotused (ptk 29-38)}

Meditsiini jagavad ühed viieks, teised kolmeks, kolmandad kaheks osaks. Ning Andreas Arvidi ütleb, et selleks, et selles asjas kindel olla, toob ta ära kõigi teiste jaotused ning pärast esitab enda oma.

Kõige tavalisem on Galenose pooldajate jaotus, mis jagab meditsiini viide ossa: füsioloogia, patoloogia, semiootika, hügieeniteadus ja terapeutika. Nendest esimene vaatleb meditsiini ainest ja eesmärki ning käib seega inimkeha, selle kõigi osade ülesehituse ja talitluse kohta, annab selgitusi nende ja ka hinge omaduste kohta. Teine (patoloogia) annab edasi haiguste ja sümptomite loomust, erinevusi ja põhjusi ning kõiki asju, millega inimkeha loomu poolest eristub. Autor lisab, et mõned arvavad, et patoloogia kuulub füsioloogia alla. 
Kolmas (semiootika) annab edasi sümptomeid, mille korral inimene on kas haige või terve, haiguse varjatud põhjusi kehas, mille põhjal võib ära tunda haiguste lõppu. Neljanda (hügieeniteaduse) vahendusel säilitatakse olemasolevat tervist ja selle abil on võimalik haigustest hoiduda. Viienda (terapeutika) abil taastatakse kaotatud tervist ning see võimaldab eemale peletada haigusi, nende põhjusi ja sümptomeid.

On ka teine meditsiini jaotus, mis jagab selle kolme ossa. Esimene tegeleb loomuomaste asjadega, teine mitteloomuomaste asjadega, kolmas ebaloomulike asjadega. Loomuomased asjad on seotud näiteks temperamentide, kehavedelike, kehaosade ja nende funktsioonidega. Mitteloomuomased asjad tulevad väljastpoolt organismi, nendeks on näiteks õhk, toit, jook, uni ja ärkvelolek, liikumine ja puhkus. Ebaloomulikeks peetakse haigusi, nende põhjusi ja sümptomeid.

Kahese jaotuse järgi jagavad mõned arstid meditsiini üldiseks ja eriliseks, mõned teoreetiliseks ja praktiliseks.

Neid jaotusi ei pea Andreas Arvidi aga õigeks ning tsiteerib taas D. Sennertit, kes väidab, et kogu meditsiin on üks distsipliin.

Andreas Arvidi lisab ka oma jaotuse. Ta väidab, et meditsiinil on kolm osa, millest esimene selgitab selle ainest, teine eesmärki ja kolmas vahendeid, mille kaudu eesmärk ja aines tarvitusele võetakse. Et meditsiin on disputatsiooni autori arvates kunst, tuleb seda käsitleda samuti nagu kunste harilikult käsitletakse, seega sõltuvalt eesmärgist, ainesest ja vahenditest. Aristotelese kohaselt tegeleb kunst millegi loomisega. Seda, mis kunsti kaudu tekib ja sünnib, nimetatakse eesmärgiks; seda, millises valdkonnas kunst midagi liikuma paneb, aineseks ja seda, mille abil kunst midagi teeb, kutsutakse vahendiks.

Kunsti puhul on vaja ainest, milles ta luuakse ja eksisteerib. On vaja ka vahendeid, sest ükski kunst ei avalda kohe mõju, mõju on juhuslik ega rända ainesest ainesesse. Niisiis on vaja vahendit, millega kompenseeritakse tegija ja osasaaja kaugust üksteisest.

Olles meditsiini osad niimoodi kindlaks määranud, tuleb Andreas Arvidi arvates vaadata kaugemale ja uurida, kas meditsiini osi saab vaadelda sellises järjekorras, nagu tema nad esitas. Autor leiab, et neid tuleb eelkõige vaadelda järjekorras nagu nad leiutati - seega kõigepealt aines, siis eesmärk ja lõpuks vahendid.

Sellest piisab Andreas Arvidi arvates meditsiini loomuse ja ülesehituse käsitlemiseks. Väitekirja lõpus on lisatud kaheksa teesi, mis püstitavad küsimusi nii praktilise ravimise kohta ja erinevate ravimite rakendamisest kui ka filosoofia ja meditsiini seostest. Näiteks küsib Andreas Arvidi, kas arst saab olla keegi, kes pole filosoof, ja annab sellele küsimusele eitava vastuse. 


\section{Kokkuvõte}

Andreas Arvidi meditsiinialane disputatsioon De natura et constitutione medicinae ei ole professionaaliks pürgiva meditsiinitudengi erialane töö, vaid asjast huvitatu harjutustöö. Sellegipoolest paistab sealt välja autori mõtteselgus ühe teadusala, s.o arstiteaduse, klassifitseerimisel ja defineerimisel. Andreas Arvidi meditsiinialane väitekiri väärib tähelepanu ka kui üliõpilase silmaringi ulatust näitav töö, disputatsioonist ilmneb autori lai haare ning eruditsioon. Viimane puudutab nii antiikkirjandust üldse kui ka kitsamalt meditsiinikirjandust antiikajast kuni Andreas Arvidi kaasaajani. Autor tsiteerib Aristotelest, Themistiost, Ovidiust, Diodorost, Pliniust ja Hippokratest ning disputatsiooni arutluskäigus on tunda Aristotelese ja Hippokratese teoste mõju. Samas tunneb Andreas Arvidi ka renessansiaja ning oma kaasaja suurte arstide töid, tsiteerides J. Fernelit, E. Bartholinust ning mitmel korral edumeelset Wittenbergi professorit iatrokeemik D. Sennertit. Et D. Sennertile viitamist esineb ka teises Academia Gustaviana meditsiinidisputatsioonis, võib järeldada, et D. Sennert oli Tartus autoriteediks ja Academia Gustavianas olid olemas mõned tema tööd. ${ }^{29}$

Siiani on Andreas Arvidi disputatsiooni De natura et constitutione medicinae käsitletud väheväärtuslikuna, tööd pole peetud isegi mitte meditsiinialaseks. Selle põhjuseks võib olla tolleaegse tüüpilise formalistliku mustri kasutamine töös. Kuna rootsiaegse Tartu ülikooli arstiteaduskonna kohta on materjali vähe, tasub olemasolevaid meditsiinialaseid töid siiski uurida tähelepanelikumalt kui seda seni on tehtud. Ehkki Andreas Arvidi meditsiinialases disputatsioonis teaduse ajaloo seisukohast midagi uut ei ole, annab selle teksti uurimine Fr. Heini meditsiinialase kõne "Oratio de medicina" kõrval kõige avarama ülevaate meditsiinialastest arusaamadest rootsiaegses Tartu ülikoolis, sest ülejäänud arstiteaduslikud tööd sellest ajast keskenduvad üksikprobleemidele.

Edasiminekuks on siin võimalusi piisavalt, nii rootsiaegse Tartu ülikooli meditsiiniväitekirjade kui ka Andreas Arvidi erinevaid teemasid käsitlevate disputatsioonide ja oratsioonide osas.

\section{Kommentaarid}

1 Nõu ja abi eest selle artikli kirjutamisel on autor tänulik Arvo Teringule ja Kristi Viidingule.

${ }^{2}$ Academia Gustavianas kaitstud väitekirjades esines tavaliselt nimetus disputatio, Academia Gustavo-Carolinas kaitstud väitekirjadest kandsid ligi pooled nimetust dissertatio ning olid üldjuhul ka lehekülgede arvult varasematest mahukamad. 
${ }^{3}$ Academia Gustaviana perioodist võib siinkohal näiteks tuua Petrus A. Schomeruse ja Magnus Ulspeckiuse töö 1634. aastast Disputatio inauguralis De anima sensitiva in genere et in specie de sensibus exterioribus (Inauguraaldisputatsioon aistivast hingest üldse ning välismeeltest eriti), Johannes Erici Stregnensise ja Faderus Arvidi Uraeliuse töö (1643) Disputatio physica de visu (Loodusteaduslik disputatsioon nägemisest) ning Johannes Erici Stregnensise ja Laurentius Erici Emzeliuse töö (1645) Disputatio physica de sensibus in genere et de auditu in specie (Loodusteaduslik disputatsioon meeltest üldse ja kuulmisest eriti).

${ }^{4}$ Paracelsus, õige nimega Philippus Aureolus Theophrastus Bombastus von Hohenheim (1493-1541), oli saksa arst ja alkeemik, iatrokeemia rajaja ning kõige olulisem mõtleja meditsiini vallas 16. sajandil. Ta on kirjutanud enam kui 200 teost, tegutses rändarstina, rahvapärimuses on ta tuntud võluri ja imearstina (Faust) (Garrison 1960: 204-208).

5 Petrus Turdinus (?-1653) õppis hiljem Tartu ülikoolis teoloogiat, oli pärast stuudiumi lõpetamist ametis kõigepealt Tartu triviaalkooli konrektorina, siis Tallinna toomkooli rektorina, seejärel Eestimaa konsistooriumi assessorina ja Ida-Harjumaa praostina (Tering 1984: 134).

${ }^{6}$ Arstiteaduse isaks peetav teadusliku meditsiini rajaja Hippokrates (u 460-370 eKr) oli pärit Kosi saarelt, talle omistatakse 58 meditsiinialasest kirjutisest koosnevat kogumikku Corpus Hippocraticum, mis sisaldab mitme arstiteaduskoolkonna õpetuse paremikku. Paraku ei saa neist kirjutistest ühtki omistada täie kindlusega Hippokratesele.

${ }^{7}$ H. Normanni ja S. G. Magilnitski artiklites (vastavalt lk 243 ja lk. 182) tuuakse ära, et J. Belowi nimetamine Academia Gustaviana meditsiiniprofessori ametisse toimus 22. detsembril 1632. a; J. Bergmani ja K. Inno käsitlused Tartu ülikooli ajaloost 17. sajandil (vastavalt lk 66 ja lk. 88) ning ka TÜA I 1982 (lk 230) väidavad, et ta asus sellel kohal tööle 1633. aastal. Tartu Ülikooli senati protokollidest aga selgub, et Johann Below võttis osa juba esimesest senati ametlikust istungist 20. oktoobril 1632 (Tering 1978: 20-21).

${ }^{8}$ Kui mitte arvestada Petrus A. Schomeruse/ Magnus Ulspeckiuse 1634. aastal Academia Gustaviana filosoofiateaduskonnas kaitstud väitekirja Disputatio inauguralis De anima sensitiva in genere et in specie de sensibus exterioribus (Inauguraaldisputatsioon aistivast hingest üldse ja välismeeltest eriti).

9 1646. on aasta, mil S. Wirdig kutsuti Tartusse vakantsele meditsiiniprofessori kohale, ametisse astus ta suurema osa autorite andmeil järgmisel, s.o 1647. aastal (Brennsohn 1905: 433, Šaurums 1932: 20, Inno 1972: 90, TÜA I 1982: 230), mõningatel andmetel aga 1648. aastal (Bergman 1932: 66).

${ }^{10}$ Esimesena omandas Tartu ülikoolis meditsiinidoktori kraadi Joseph August Hassenmueller doktoriväitekirjaga Novum remedium ad curationem trichiaseos (Uus vahend trihhiaasi ravimiseks).

11 Johannes Gezelius (1615-1690) oli Academia Gustaviana kreeka ja heebrea keele professor ja üks väljapaistvaimaid teadlasi. Hiljem oli ta Turu peapiiskopi ametis (Päll 2005: 93).

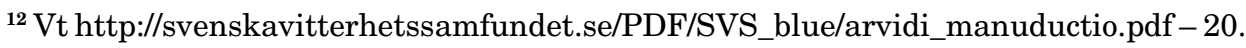
juuni 2008.

${ }^{13}$ Luuletusi vt ka http://www.ut.ee/klassik/neolatina/1648.htm (20. juuni 2008) ja Viiding 2002: 260-277. 
${ }^{14}$ Album Academicumi andmetel on Andreas Arvidi pidanud kolm oratsiooni, millest esimese daatumiks on märgitud 02. 05. 1642. Tegelikult polnud ta sel ajal veel ülikooli astunudki ning selle kõne kohta pole ka Academia Gustaviana trükiseid puudutavates bibliograafiates mingeid andmeid.

${ }^{15}$ Andreas Arvidi disputatsioonide ja oratsioonide loetelu Academia Gustavianas nende toimumise järjekorras on järgmine.

Disputatsioonid:

1) 30. 03. 1644. a, eesistuja astronoomiaprofessor Johannes Erici Stregnensis. Discursus astrologicus de causis mutationis aeris et tempestatum generalibus et specialibus ubi simul adduntur quaedam exempla ad certos dies trium subsequentium mensium aestivalium currentis hujus an. 1644 ex quibus causae istae confirmantur et de aeris mutatione ad illos dies naturaliter praedicere possumus (Astroloogiline diskursus ilma muutumise üldistest ja erilistest põhjustest, kus ühtlasi lisatakse mõni näide jooksva 1644. aasta kolme järjestikuse suvekuu teatavate päevade kohta, mis kinnitavad neid põhjusi ja mille põhjal võime loodusseaduse järgi ennustada ilma muutumist nende päevade ajal), $24 \mathrm{lk}$.

2) 31. 08. 1644. a, eesistuja astronoomiaprofessor Johannes Erici Stregnensis. Theses de diebus canicularibus (Teesid põuaperioodist), $12 \mathrm{lk}$.

3) 27. 09. 1645. a, eesistuja matemaatikaprofessor Joachim Schelenius. Disputatio de natura mathesios (Disputatsioon matemaatika loomusest), $12 \mathrm{lk}$.

4) ?. 10. 1647. a, eesistuja astronoomiaprofessor Johannes Erici Stregnensis. Disputatio physica de plantis (Loodusteaduslik disputatsioon taimedest), $16 \mathrm{lk}$.

5) 02. 09. 1648. a, eesistuja meditsiiniprofessor Sebastian Wirdig. Disputatio medica de natura et constitutione medicinae (Meditsiinialane disputatsioon meditsiini olemusest ja ülesehitusest), $28 \mathrm{lk}$.

6) 27. 10. 1648. a, eesistuja kreeka ja heebrea keele professor Johannes Gezelius. Disputatio ethica de fortitudine (Eetikaalane disputatsioon vaprusest), 12 lk.

Oratsioonid:

1) 16. 12. 1644. a De lykanthropis oratio (Oratsioon libahuntidest), $24 \mathrm{lk}$.

2) 10. 11. 1647. a Martini Lutheri, theologiae doctoris et professoris in Academia

Witebergensi elogia (Teoloogiadoktori ja Wittenbergi ülikooli professori Martin Lutheri kiitus), $24 \mathrm{lk}$.

16 Jean Fernel (1497-1558) oli prantsuse astronoom, matemaatik ja arst. Et ta oli oma sajandi üks suurimaid arste, nimetati teda kaasaegseks Galenoseks. J. Fernel oli esimese kaasaegse psühholoogiaalase 1542. aastal ilmunud uurimusliku monograafia De naturali parte medicinae (Meditsiini loomulikust osast) autor. Ühtlasi oli ta Prantsusmaa kuninga Henri II ihuarst (Robert 1975: 648).

17 Themistios, kelle eluaastad olid umbes 317-388 pKr, tegutses Konstantinoopolis ning õpetas seal Platoni ja Aristotelese filosoofiat. Temalt on säilinud Aristotelese teoste parafraase ja 33 poliitilise sisuga kõnet. Et tema teoseid on Eestis vähe, ei õnnestunud paraku kindlaks teha Themistiose tsitaadi täpset asukohta.

${ }^{18}$ Daniel Sennert (1572-1637) oli Wittenbergi ülikooli meditsiiniprofessor, silmapaistev õpetlane, tuntud iatrokeemik, kes mitmes töös püüdis ühendada Paracelsuse 
õpetust Galenose omaga (TÜA I 1982: 232). Muuhulgas kirjeldas ta 1629. aastal alkoholismi tagajärgi (Garrison 1960: 823).

${ }^{19}$ Kreeka päritolu Galenos (129-199 pKr) oli tuntuim Vanas-Roomas tegutsenud arst. Ta oli Rooma keisrikoja ihuarst, oma teostes võttis ta kokku kõik senised meditsiiniteadmised ja kommenteeris kõiki Hippokratese teoseid. Tema õpetusel oli suur mõju renessansiajani.

${ }^{20}$ Hermes Trismegistos oli Egiptuse kuu- ja tarkusejumala Thothi teisend hilisantiikajal. Hermeselt usuti pärinevat hellenismi ja hilisantiikaja usulisi ja filosoofilisi teoseid. Peale mõne kopti- ja ladinakeelse teose on säilinud kreekakeelne Corpus hermeticum. See koosneb 17 või 18 teosest, millest olulisim on Poimandres (2.-3. sajand). Hermest peeti suureks võluriks, kes oma imepitsatiga võivat sulgeda nt anumaid ligipääsmatult.

${ }^{21}$ Nimi Apis tähistas nii mitmeid antiikaja linnu kui ka tegelasi egiptuse ja kreeka mütoloogias. Tuntuim Apis oli egiptuse usundis jumalana austatud härg, viljakuse tooja. Siin on aga ilmselt mõeldud Aischylose tragöödias "Palujannad" (värss 262 ja edasi) esinevat Apist, kes oli jumal Apolloni poeg ning arst ja selgeltnägija, kes elu lõpul suundus Egiptusse ja asutas seal Memphise linna. Teda peeti ka esimeseks arstiks.

${ }^{22}$ Diodoros, ka Diodorus Siculus (umbes $80 \mathrm{eKr}-29 \mathrm{pKr}$ ), koostas 40 raamatust koosneva teose Ajalooline raamatukogu, mis käsitleb maailma ajalugu müütilisest ajast kuni Caesari ajani.

${ }^{23}$ Diodorose teoses I rmt ptk 16 on üles loetud hulk asju ja nähtusi, mis olevat Hermese leiutatud (näit artikuleeritud inimkeel, tähestik, lüüra), kuid meditsiini nende hulgas pole.

${ }^{24}$ Plinius Vanem (23/24-79 pKr) oli rooma riigiametnik, sõjaväeülem, ajaloolane ja kirjanik, kes hukkus Vesuuvi purske ajal. Tema rohketest teostest on säilinud entsüklopeedia Naturalis historia (Looduslugu), mis koosneb 37 raamatust.

${ }^{25}$ Arabos oli jumal Apolloni ja Babyloni nimelise tütarlapse poeg, keda Plinius Vanema Loodusloo VII rmt 196. ptk on nimetatud meditsiini leiutajaks (Plinius 1989: 638/639).

${ }^{26}$ Publius Ovidius Naso (43 eKr - u $18 \mathrm{pKr}$ ) oli väljapaistvaimaid rooma luuletajaid, kelle peateosed on Metamorphoses ja Fasti.

${ }^{27}$ Erasmus Bartholinus (1625-1698) oli taani loodusteadlane, Kopenhaageni ülikooli matemaatika- ja meditsiiniprofessor.

${ }^{28}$ Epistulae ex Ponto (Kirjad Musta mere äärest) I rmt III kiri, read 16-17.

${ }^{29}$ Esimesi andmeid D. Sennerti teoste olemasolu kohta Academia Gustavianas võib leida aastast 1651 (Puksov 1932: 259-260), seega Andreas Arvidi meditsiinialase disputatsiooni valmimise aja kohta seda kindlalt väita ei saa. 


\section{Kasutatud kirjandus}

Aristoteles $1990=$ Aristotle. The Nicomachean Ethics. H. Rackham (tõlk). The Loeb Classical Library. Cambridge, Massachusetts, London: Harvard University Press.

Bergman, Johan 1932. Universitetet i Dorpat under svenska tiden. Upsala-Stockholm: Almquist \& Wiksell.

Brennsohn, Isidor 1905. Die Aerzte Livlands von den ältesten Zeiten bis zur Gegenwart ein biographisches Lexikon. Mitau: J. F. Steffenhagen.

Constitutiones 1997 = Constitutiones Academiae Dorpatensis (Academia Gustaviana). Tartu Akadeemia (Academia Gustaviana) põhikiri. Kristi Sak (tõlk), Marju Lepajõe (toim). Tartu: Tartu Ülikooli Kirjastus.

Garrison, Fielding Hudson 1960. An Introduction to the History of Medicine. Philadelphia and London: W. B. Saunders Company.

Hein, Friedrich 1637. Oratio de medicina. Dorpati Livonorum: Lit. Acad.

Hippokrates 1981 = Hippocrates I. W. H. S. Jones (tõlk). The Loeb Classical Library. Cambridge, Massachusetts: Harvard University Press, London: William Heinemann LTD, 1981, lk 255-265.

Hippokrates 1984 = Hippocrates. W. H. S. Jones (tõlk). I kd. The Loeb Classical Library. Cambridge, Massachusetts: Harvard University Press, London: William Heinemann LTD, 1984, lk 70-137.

Inno, Karl 1972. Tartu University in Estonia during the Swedish Rule (1932-1710). Estonian Science in Exile. New Edition nr 2 (4). Stockholm: Förlag Vaba Eesti.

Jaanson, Ene-Lille 2000. Tartu Ülikooli trükikoda 1632-1710. Ajalugu ja trükiste bibliograafia. Druckerei der Universität Dorpat 1632-1710. Geschichte und Bibliographie der Druckschriften. Tartu Ülikooli Raamatukogu. Tartu: OÜ Greif.

Johannisson, Karin 1989. Levande lärdom. Uppsala universitet under fem sekler. Uddevalla: Uppsala University Press.

Käbin, Ilo 1986. Die medizinische Forschung und Lehre an der Universität Dorpat/ Tartu 1802-1940. Ergebnisse und Bedeutung für die Entwicklung der Medizin. Lüneburg: Nordostdeutsches Kulturwerk.

Lill, Anne 1994. Latin at the University of Tartu (Dorpatum) in the seventeenth century. Merisalo, Outi \& Sarasti-Wilenius, Raija (toim). Mare Balticum-Mare nostrum. Latin in the Countries of the Baltic Sea (1500-1800). Annales Academiae Scientiarum Fennicae, ser B nr 274. Helsingfors: Suomalainen Tiedeakatemia, lk 97-105.

Loit, Aleksander 2006. Ühiskondlike vastuolude peegeldus Tartu-Pärnu rootsiaegse ülikooli tegevuses (1632-1710). Läänemere provintside arenguperspektiivid Rootsi suurriigis 16./17. sajandil. Eesti Ajalooarhiivi toimetised 12 (19). Tartu: Eesti Ajalooarhiiv, lk 123-150.

Magilnitski 1967 = Магилницкий, С. Г. 1967. Медики университетов в Тарту и Пярну в XVII-XVIII вв (1632-1710). Нз истории медицины nr 7. Рига, lk 179-188. 
Normann, Herbert 1926. Märkusi rootsiaegsest Tartu ülikooli arstiteaduskonnast. Eesti Arst, nr 7, lk 241-247.

Plinius 1989 = Pliny. Natural History in Ten Volumes II. Libri III-VII. Rackham, H. (tõlk). The Loeb Classical Library. Cambridge, Massachusetts, London: Harvard University Press, lk 505-651.

Puksov, Friedrich 1932. Die Bibliothek der Universität Tartu und Tartu-Pärnu in der Schwedenzeit. Sitzungsberichte der Gelehrten Estnischen Gesellschaft 1931. Tartu, lk 251-282.

Päll, Janika 2003. Vanakreeka keel Tartu Ülikoolis 1632-1710. Kakssada aastat klassikalist filoloogiat Eestis = Duo saecula philologiae classicae in Estonia. Morgensterni Seltsi toimetised, I. Tartu: Tartu Ülikooli Kirjastus, lk 19-47.

Päll, Janika 2005. Far away from Byzantium: Pronunciation and Orthography of Greek in the 17th Century Estonia. Byzantino-Nordica 2004. Papers presented at the international symposium of Byzantine studies held on 7-11 May 2004 in Tartu, Estonia. Morgensterni Seltsi toimetised, II. Tartu: Tartu University Press, lk 86-119.

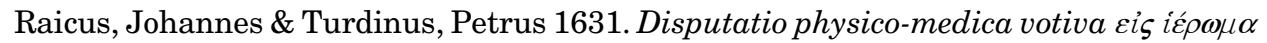
surgenti jam Dorpati novo collegio regio. Rigae Livonum: G. Schröder.

Recke, Johann Friedrich von \& Napiersky, Karl Eduard 1831. Allgemeines Schriftstellerund Gelehrten-Lexikon der Provinzen Livland, Esthland und Kurland. Mitau: J. F. Steffenhagen u. Sohn.

Robert 1975 = Le petit Robert 2 sous la direction de Paul Robert. 1975. Paris, lk 648.

Sainio, Matti A. 1978. Dissertationen und Orationen der Universität Dorpat 16321656. Årsböcker $i$ svensk undervisningshistoria. LVIII aastakäik, nr 141. Stockholm: Ljunbergs Boktryckeri AB.

Sainio, Matti A. 1993. Andreas Arvidi als Student in Tartu. Die schwedischen Ostseeprovinzen Estland und Livland im 16.-18. Jahrhundert. Acta Universitatis Stockholmiensis. Studia Baltica Stockholmensia 11. Stockholm: Almquist \& Wiksell, lk 277284.

Stregnensis, Johannes Erici \& Stregnensis, Andreas Arvidi 1647. Disputatio physica de Plantis. Dorpati Livonorum: J. Vogelius.

SBL 1918 = Svenskt biografiskt lexikon. 1918. 1. kd, Abelin-Anjou, Stockholm.

Šaurums, Gustavs 1932. Tērbatas Universitāte 1632-1932. Rīga.

Tering, Arvo 1984. Album Academicum der Universität Dorpat (Tartu) 1632-1710. Publicationes Bibliothecae Universitatis Litterarum Tartuensis V. Tallinn: Valgus.

Tering, Arvo 1978. Tartu Ülikooli (Academia Gustaviana) senati protokollid 1632-1656. Konsistoriumsprotokolle der Universität Dorpat (Academia Gustaviana) 1632-1656. I 1632-1634. Publicationes Bibliothecae Universitatis Litterarum Tartuensis IV. Tartu: TRÜ trükikoda.

Tering, Arvo 1994. Tartu Ülikooli (Academia Gustaviana) senati protokollid 1632-1656. Konsistoriumsprotokolle der Universität Dorpat (Academia Gustaviana) 1632-1656. 
II 1637-1644. Publicationes Bibliothecae Universitatis Litterarum Tartuensis VII. Tartu: Tartu Ülikool Kirjastuse trükikoda.

Triebs, Michaela 1995. Die Medizinische Fakultät der Universität Helmstedt (15761810). Herausgegeben von der Herzog August Bibliothek. Wiesbaden: Harrassowitz Verlag.

TÜA I 1982 = Tartu Ülikooli ajalugu I 1632-1798. Helmut Piirimäe (koost). Tallinn: Valgus.

Viiding, Kristi 2002. Die Dichtung Neulateinischer Propemptika ad der Academia Gustaviana (Dorpatensis) in den Jahren 1632-1656. Tartu: Tartu Ülikooli Kirjastus.

Viiding, Kristi 2005. Õnnelik olgu su samm... Keel ja Kirjandus nr 6, lk 455-461.

Wirdig, Sebastian \& Oestenius, Olaus 1651. Disputatio medica de dysenteria. Dorpati Livonorum: J. Vogelius.

Wirdig, Sebastian \& Stregnensis, Andreas Arvidi 1648. Disputatio medica de natura et constitutione medicinae. Dorpati Livonorum: J. Vogelius.

\section{Summary}

\section{De natura et constitutione medicinae by Andreas Arvidi as a Mirror of Medical Thought at the 17th-Century University of Tartu}

\section{Kaarina Rein}

Key words: 17 th-century disputations, history of medicine, medical education at the University of Tartu in the Swedish period, "Stregensis" by Andreas Arvid, studying at Academia Gustaviana Dorpatensis.

The present article deals with a medical disputation, written and defended at the University of Tartu during its first period of activity in the 17th century, when the university was called Academia Gustaviana. More precisely, under investigation is the disputation of the Swedish poetry theorist Andreas Arvidi (ca 1620-1673), De natura et constitutione medicinae, and its context. The medical education was at the insufficient level at most 17th-century universities in Europe and this was the case at the University of Tartu as well. There were very few students of medicine at the University of Tartu during the Academia Gustaviana period (eight, all in all) compared to the whole number of students (1056) during that time. Only two of these eight students were afterwards active as physicians. There were but few medical disputations defended during the Academia Gustaviana period, of which two were solely medical, supervised by the professor of medicine Sebastian Wirdig. The first of these, the disputation by Andreas Arvidi, deals with medicine in general. Andreas Arvidi was not a medical student but studied natural sciences at the University of Tartu. As a person of 
great talent, he debated on a variety of themes, including astronomy, mathematics, botany, medicine and ethics. His disputation De natura et constitutione medicinae is explaining the meaning of the word 'medicine' by exposing its etymology and providing synonyms and homonyms to this word. In defining medicine he quotes Jean Fernel, the famous French Renaissance physician. Then he discusses the reasons and purposes for inventing medicine and finally presents the systematisation of medicine. The whole work reveals the author's brilliant knowledge of Greek and Roman authors, as well as of contemporary medical authorities. Of the latter ones, iatrochemist Daniel Sennert, professor at Wittenberg University, has been quoted on several occasions, which implies to the fact that Sennert was an authority in the 17th-century Faculty of Medicine in Tartu. Andreas Arvidi's disputation De natura et constitutione medicinae is a work that gives the broadest overview of medical thought at the University of Tartu in the 17 th century. 